\title{
A expansão da União Européia em 2004 e seus impactos no agronegócio brasileiro
}

Samuel José de Magalhães Oliveira ${ }^{1}$ Joaquim Bento de Souza Ferreira Filho²

Resumo: O comércio internacional tem adquirido importância crescente ao Brasil, especialmente para ao setor rural. Assim, entender o impacto da política de terceiros países no agronegócio brasileiro é importante. A União Européia (UE) é um dos principais parceiros comerciais do Brasil e é conhecida pela grande interferência que impõe ao seu setor agrícola na forma de diversos subsídios. O impacto da expansão da UE em 2004 e a reforma da Política Agrícola Comum (PAC) têm sido estudados em muitas regiões do mundo, mas não exaustivamente no Brasil. Este trabalho objetiva determinar o impacto da expansão da EU em 2004 no agronegócio brasileiro utilizando o Modelo de Equilíbrio Geral (GTAP) Projeto de Análise do Comércio Global -, sob três cenários alternativos de reforma da PAC. Os impactos setoriais mais importantes foram sentidos na própria UE, como esperado, já que as medidas ocorrem naquele bloco. O impacto agregado da expansão da UE não foi importante para a economia brasileira. Mas, diferentes medidas da UE afetaram setores específicos do agronegócio brasileiro, como oleaginosas e carne bovina. As exportações desses setores da economia cresceram com a expansão e o descasamento dos pagamentos diretos, embora tenham decrescido com a expansão da UE sem o descasamento.

Palavras-chave: economia internacional; comércio internacional; equilíbrio geral; integração econômica.

\footnotetext{
${ }^{1}$ Doutor em Economia. Embrapa Rondônia. E-mail: samuel@cpafro.embrapa.br ${ }^{2}$ Doutor em Economia. Universidade de São Paulo. Departamento de Economia, Administração e Sociologia, da Esalq/USP. E-mail: jbsferre@esalq.usp.br
} 
Abstract: International trade has acquired increasing importance for the Brazilian economy, especially for agribusiness. In this way, understanding other countries policies that affects international trade and its impacts in this country is equally important. The European Union (EU) is one of the most important Brazilian trade partners and it is known by strong interference on its agricultural sector. The recent European enlargement and the last Common Agricultural Policy (CAP) Reform have been studied at different regions of the World but there is a lack of knowledge regarding the impacts of this on Brazilian rural sectors. This paper aims to assess the impacts of the 2004 EU enlargement on Brazilian agribusiness using the general equilibrium model Global Trade Analysis Project (GTAP) under three alternatives scenarios for CAP Reform. The sectoral impacts were more relevant within the EU, as expected, as the measures take place in this region. The aggregate impact of the enlargement with or without decoupling was not important for the Brazilian economy. But it was found that different policies affect some Brazilian agribusiness sectors performance as oilseeds and bovine meat. Exports from these Brazilian sectors grow with enlargement as decoupling takes place, though they decrease under enlargement without decoupling.

Key-words: international economics; international trade; general equilibrium; economic integration.

Classificação JEL: F11, F15, Q17.

\section{Introdução}

A expansão da União Européia (UE) ocorrida em 2004 foi a que envolveu o maior número de nações entre todas que já aconteceram. Dez países se juntaram à UE, que passou a ser um dos mais importantes e extensos espaços econômicos do planeta. Essa integração leva à extensão das políticas comercial, externa e agrícola da UE para esses novos países. Entre elas, se destaca a Política Agrícola Comum (PAC), um dos principais mecanismos de intervenção agrícola.

As origens da União Européia remontam ao período pós-Segunda 
Guerra Mundial. Em 1950, o primeiro ministro francês Robert Schuman propõe a criação de um órgão que integrasse a produção de carvão e aço na Europa, buscando saída política e econômica aos problemas enfrentados pelo continente europeu. França, Alemanha Ocidental, Itália, Holanda, Bélgica e Luxemburgo assinam, em Paris, o Tratado que estabelece a Comunidade Européia do Carvão e do Aço (Ceca), que começa a funcionar em 1952. O sucesso da Ceca leva estas mesmas seis nações a aprofundarem a integração econômica e política. Assim, em 1957, assinam os Tratados de Roma que estabelecem, a partir de 1958, a Comunidade Econômica Européia (CEE) e Comunidade Européia de Energia Atômica (Euratom), com sede em Bruxelas, na Bélgica. Os objetivos iniciais da CEE eram a remoção de barreiras comerciais entre os Estados-Membros e a formação de um mercado comum. A Euratom, como o nome sugere, tratava de questões relacionadas à energia nuclear de maneira integrada entre os Estados-Membros. Esses três organismos passaram por sucessivas modificações de atribuições, visando a maior integração política e econômica entre os diversos países europeus. Também houve, a partir de 1973, sucessivos processos de expansão dessa comunidade de nações. Em 1967, as três comunidades são fundidas em apenas uma, a Comunidade Européia, que, após novas mudanças estruturais ocorridas em 1992, dá origem à União Européia (UE). Em maio de 2004, a UE assiste à sua maior expansão, com a acolhida de dez novos membros, na maioria, antigos países socialistas integrantes do Pacto de Varsóvia. São eles: Letônia, Lituânia e Estônia, no Báltico; Polônia, Hungria, República Tcheca, Eslováquia e Eslovênia, na Europa Central, e Malta e Chipre, no Mediterrâneo. O Ato de Ascensão e o critério de Copenhague são importantes fontes para a definição dos termos dessa expansão, incluindo a implementação da PAC nos novos membros, com sua reforma em curso (Cronology..., 2005; History..., 2005; The Churchill Society, London, 2005).

A PAC é esboçada a partir do Tratado de Roma, em 1957, e começa a vigorar em 1962. Dada a então recente experiência européia de desabastecimento agrícola, buscou-se, de início, incentivar a produção de alimentos e matérias-primas nos países-membros da CEE, dificultando a importação e garantindo preço ao produtor acima do mercado internacional. Nos anos 70, a produção agrícola européia não só já abastecia 
os países integrantes da Comunidade Européia como começava a gerar excedentes exportáveis. A colocação desses excedentes no mercado internacional passou a ser estimulada através de subsídios à exportação. Isso gerou volume de produção cada vez maior, que passou a inundar o mercado internacional. Tal fato causou insatisfação em outros países exportadores de produtos agrícolas, entre eles o Brasil. As negociações européias na Organização Mundial do Comércio (OMC), criada em 1994, e o custo crescente da PAC levantaram vozes a favor de reformas na Política Agrícola também no próprio continente europeu. Assim, a partir da década de 1990, reformas são implementadas no sentido de diminuírem a interferência oficial na produção agropecuária européia, como a diminuição dos preços de intervenção, o estabelecimento de cotas de produção, áreas de descanso compulsórias e de pagamentos diretos. Esses últimos são transferências criadas para compensar a gradual diminuição do suporte direto a preço, um dos fundamentos iniciais da PAC. São pagos na forma de subsídio à terra, ao abate de animais, entre outras.

A última reforma da PAC, ocorrida em 2003, apresentou como maior novidade o descasamento dos pagamentos diretos recebidos por produtores rurais. Desse modo, a renda garantida à unidade de produção se desvincularia da quantidade produzida. O descasamento é medida que visa substituir todos os pagamentos diretos por uma única subvenção, atrelada ao histórico dos subsídios recebidos pela unidade de produção, mas desvinculada da quantidade produzida. É uma medida complexa, de implantação lenta, que enfrenta resistência de grupos organizados e está permeada de exceções.

Com essa última reforma, a função da agricultura e do meio rural na União Européia passa a ser vista não apenas como a produção de alimentos, mas também a segurança do consumidor, a preservação do meio ambiente e do meio rural. É o conceito da multifuncionalidade da agricultura. Além disso, a reforma busca transferir subsídios da produção para medidas que visem o desenvolvimento rural e a preservação do meio ambiente, a chamada modulação (Blanton, 2005; European Union, 2003; OECD, 2004; OXFAM, 2002; RAO, 2005).

Estudando as conseqüências da expansão de 2004, Gabrish (1997) prevê ajuste de preços, salários e transferências para as novas economias que se integram à UE. No entanto, ressalta que todo esse ajuste 
pode não redundar em crescimento econômico acelerado, como esperado por alguns, nos novos países-membros. Tal fato já foi observado quando se associaram Grécia, Espanha, Portugal e Irlanda. Keuschnigg, Keuschnigg e Kohler (2001) avaliaram os impactos da expansão européia na Alemanha, através de um modelo de equilíbrio dinâmico e ressaltaram que muitos temores de aumento de déficit fiscal na UE e concorrência de produtos intensivos em trabalho provenientes do leste europeu são infundados. A expansão européia proporciona novas oportunidades de investimento para o país e expansão da atividade produtiva alemã. Dyker (2001) concorda que o crescimento econômico esperado para os novos Estados-membros não deve ser muito elevado, a curto prazo. A longo prazo, porém, o ganho de escala conseguido pelas integração dessas economias à UE pode resultar em maiores oportunidades de crescimento, se os novos membros souberem aproveitar a realidade de pertencer a um mercado de maior dimensão. $\mathrm{O}$ autor espera, ainda, que a expansão de 2004 não traga crescimento econômico significativo para a UE, em termos agregados, pela pequena dimensão econômica dos novos países-membros. No entanto, ressalta que importantes variações na produção de alguns setores e de alguns países podem ser observadas.

Bchir, Fontagné e Zanghieri (2003) estudaram o impacto da expansão de 2004 na UE, utilizando o modelo de equilíbrio geral, o Mirage, que trata de maneira detalhada a estrutura de mercado, incluindo a competição imperfeita. Concluíram que o maior benefício esperado se localiza nos novos membros, que se associam a uma ampla região já integrada. Os ganhos advêm de maior fluxo de capitais e da expansão dos mercados. O maior impacto nos novos países-membros provém da extensão da PAC a eles. Paas e Tafenau (2005), utilizando modelo gravitacional, concluem que a expansão européia de 2004 tem potencial de aumentar o fluxo de comércio na região e transferência tecnológica entre os membros da UE. Os autores encontraram forças gravitacionais tradicionais que explicam a evolução do comércio internacional entre os países, como tamanho da economia, população e distância, relações históricas entre os países e cooperação entre os mesmos.

Cochrane e Seeley (2004) determinaram o impacto da expansão européia na produção agrícola e concluíram que, de fato, a produção de carne 
bovina e grãos para alimentação animal pode aumentar nos novos paísesmembros da UE. Kohler (2004) estudou o impacto da expansão de 2004 nos atuais membros da UE criando um modelo econométrico. Concluiu que a expansão proporciona melhoria do bem-estar nos antigos membros equivalente a apenas $0,3 \%$ do produto nacional bruto dos mesmos.

Muitos autores avaliaram as implicações da expansão da UE utilizando o Modelo de Equilíbrio Geral (GTAP) (Jensen, Frandsen e Bach, 1998; Herok e Lotze, 2000; Jensen e Frandsen, 2003; Antimiani e Santuccio, 2004). Esse modelo foi desenvolvido para determinar o impacto dos fluxos comerciais em diferentes setores e regiões do mundo, gerando resultados de consistência global (Hertel, 1997). Os estudos realizados, no entanto, quase sempre focalizam a própria União Européia e outras regiões nas quais o Brasil não consta de maneira desagregada, não gerando resultados específicos para esta nação emergente no mercado internacional de produtos agrícolas.

Estudos têm sido conduzidos para avaliar os impactos da reforma da PAC utilizando a abordagem de equilíbrio geral, equilíbrio parcial ou mesmo programação matemática (Binfield; Westhoff; Young II, 2003). Alguns resultados ressaltam que mais esta reforma da PAC, mantendo o princípio de subsídios elevados à unidade de produção, não terá grande impacto na produção e comércio exterior de muitos produtos agrícolas, em termos agregados para a União Européia. Para algumas commodities, cuja produção se encontra mais atrelada ao subsídio, como carne bovina e leite, espera-se maior impacto. A produção de carne bovina na União Européia pode diminuir $4 \%$ até 2012. A produção e a exportação de produtos lácteos também devem decrescer (Binfield et al., 2005; Food and Agricultural Policy Center - Fapri, 2003).

Avaliar os impactos da reforma da PAC e da expansão da UE no Brasil, especialmente no agronegócio, é necessário, e se trata do objetivo deste trabalho. Procura-se entender as conseqüências de mudanças institucionais da UE no meio rural brasileiro, com a utilização de um modelo aplicado de equilíbrio geral. 


\section{Metodologia}

\subsection{Visão geral do modelo GTAP}

O estudo foi conduzido com o auxílio do Modelo de Equilíbrio Geral (GTAP). O GTAP está em contínuo desenvolvimento, e o projeto é inovador, visto que apresenta ampla publicidade dos modelos e base de dados gerados, incentiva a formação de uma rede de colaboradores e evita o trabalho repetido e isolado. Essas características são indispensáveis para o contínuo aprimoramento do projeto, com sua reconhecida complexidade. Encontram-se disponíveis na internet informações detalhadas sobre o modelo e centenas de estudos conduzidos com sua utilização (GTAP, 2006; Hertel, 1997).

O GTAP é composto por equações que, simplificadamente, retratam o comportamento dos agentes econômicos, e uma base de dados que espelha os recursos disponíveis e a produção em um determinando momento. O modelo é clássico, admitindo, pois, concorrência perfeita e ausência de economia de escala, o que é uma simplificação da realidade. O GTAP assume que cada setor da economia produz um só produto, e o estoque de terra, trabalho e capital (fatores básicos) é fixo em cada região, embora se movimentem entre os setores. A demanda de cada setor por fatores básicos e insumos intermediários segue a função de Leontieff de proporções fixas. A origem dos insumos em cada setor, doméstica ou importada e a origem do importado seguem a abordagem de Armington, com elasticidade de substituição constante. A versão atual do modelo contempla 57 setores em 87 regiões do mundo e está ajustada para o ano de 2001, embora as matrizes insumo-produto de cada uma das regiões sejam de datas distintas (GTAP, 2006; Hertel, 1997).

\subsection{Agregação regional e setorial}

A agregação regional deste estudo compreende 14 regiões - o Brasil consiste em uma distinta. Duas regiões são os novos membros da UE e cinco, os antigos membros. As outras seis abarcam outras regiões do mundo (Tabela 1). 
Tabela 1. Agregação regional utilizada no estudo

\begin{tabular}{|c|c|c|c|}
\hline$n^{o}$ & código & descrição da região & Regiões originais GTAP \\
\hline 1 & Brasil & Brasil & bra \\
\hline 2 & Polônia & Polôni & pol \\
\hline 3 & RUE10 & $\begin{array}{l}\text { novos membros da UE, exceto } \\
\text { a Polônia }\end{array}$ & $\begin{array}{l}\text { cyp cze hun mlt svk svn } \\
\text { est lva ltu }\end{array}$ \\
\hline 4 & Escand & Dinamarca, Finlândia e Suécia & dnk fin swe \\
\hline 5 & Atlant & $\begin{array}{l}\text { Reino Unido, Irlanda, Bélgica, } \\
\text { Holanda e Luxemburgo }\end{array}$ & bel gbr irl lux nld \\
\hline 6 & Aleaus & Alemanha e Áustria & aut deu \\
\hline 7 & Franca & França & fra \\
\hline 8 & Medite & Grécia, Itália, Portugal e Espanha & grc ita prt esp \\
\hline 9 & Nafta & Estados Unidos, Canadá e México & can usa mex \\
\hline 10 & Argent & Argentina & $\arg$ \\
\hline 11 & China & China & chn hkg \\
\hline 12 & RAsia & demais países da Ásia & $\begin{array}{l}\text { jpn kor twn xea idn mys phl sgp } \\
\text { tha vnm xse bgd ind lka xsa tur xme }\end{array}$ \\
\hline \multicolumn{4}{|r|}{ s } \\
\hline \multirow[t]{2}{*}{14} & RAmeri & demais países da América & $\begin{array}{l}\text { xna col per ven xap chl ury xsm xca } \\
\text { xfa xcb }\end{array}$ \\
\hline & ROW & demais países do Mundo & $\begin{array}{l}\text { aus nzl xoc che xef xer alb bgr hrv } \\
\text { rom rus xsu mar tun xnf bwa zaf } \\
\text { xsc mwi moz tza zmb zwe xsd } \\
\text { mdg uga xss }\end{array}$ \\
\hline
\end{tabular}

Fontes: Dados da pesquisa

Os 25 setores considerados neste estudo se encontram na Tabela 2 . A ênfase do detalhamento setorial é dada para o agronegócio. 
Tabela 2. Agregação setorial utilizada no estudo

\begin{tabular}{|c|c|c|c|}
\hline $\mathbf{n}^{\mathbf{o}}$ & código & descrição do setor & setores originais GTAP \\
\hline 1 & trigo & trigo & wht \\
\hline 2 & ocerea & outros cereais, inclusive milho & gro \\
\hline 3 & fruveg & $\begin{array}{l}\text { frutas e vegetais, inclusive laranja e suco } \\
\text { de laranja }\end{array}$ & v_f \\
\hline 4 & oleagi & $\begin{array}{l}\text { oleaginosas, inclusive soja, não inclui farelo } \\
\text { de soja }\end{array}$ & osd \\
\hline 5 & fibveg & fibras vegetais & $\mathrm{pfb}$ \\
\hline 6 & ccdcul & café, cacau e demais cultivos & ocr \\
\hline 7 & bovovi & $\begin{array}{l}\text { bovinos, ovinos, caprinos, eqüinos, asininos } \\
\text { e muares }\end{array}$ & ctl \\
\hline 8 & frasui & frangos, suínos e demais animais & oap \\
\hline 9 & leite & leite & $\mathrm{rmk}$ \\
\hline 10 & laseda & lã e seda & wol \\
\hline 11 & evsilv & extrativismo vegetal e silvicultura & frs \\
\hline 12 & pesca & produtos de pesca & fsh \\
\hline 13 & eminer & extrativismo mineral & coa oil gas omn \\
\hline 14 & cbovov & $\begin{array}{l}\text { carne de bovinos, ovinos, caprinos, eqüinos, } \\
\text { asininos e muares }\end{array}$ & $\mathrm{cmt}$ \\
\hline 15 & cfrasu & carne de frango, suíno e demais animais & omt \\
\hline 16 & govege & gorduras e óleos vegetais, inclusive torta e farelo & vol \\
\hline 17 & latici & laticínios & mil \\
\hline 18 & arroz & arroz em casca e processado & pdr pcr \\
\hline 19 & acucar & $\begin{array}{l}\text { cultivo de cana-de-açúcar, beterraba e produção } \\
\text { industrial de açúcar }\end{array}$ & c_b sgr \\
\hline 20 & dpalim & indústria de produtos alimentícios, exceto açúcar & ofd \\
\hline 21 & bebtab & indústria de bebidas e tabaco & b_t \\
\hline 22 & pquimi & $\begin{array}{l}\text { indústria de produtos químicos, incluindo } \\
\text { fertilizantes }\end{array}$ & crp \\
\hline 23 & mequipa & $\begin{array}{l}\text { indústria de máquinas e equipamentos, } \\
\text { incluindo de uso agrícola }\end{array}$ & ome \\
\hline 24 & oindus & $\begin{array}{l}\text { todos os demais setores industriais não } \\
\text { citados acima como construção civil, têxteis, } \\
\text { vestuário,madeira e papel, veículos e } \\
\text { equipamentos eletrônicos, entre outros }\end{array}$ & $\begin{array}{l}\text { tex wap lea lum ppp p_c } \\
\text { nmm i_s nfm fmp mvh otn } \\
\text { ele omf }\end{array}$ \\
\hline 25 & servic & $\begin{array}{l}\text { setor de serviços, incluindo serviços públicos, } \\
\text { privados, financeiros, transporte, entre outros }\end{array}$ & $\begin{array}{l}\text { ely gdt wtr cns trd otp wtp atp } \\
\text { cmn ofi isr obs ros osg dwe }\end{array}$ \\
\hline
\end{tabular}

Fontes: Dados da pesquisa 


\subsection{Modelagem}

Foram consideradas as mudanças institucionais decorrentes da expansão da UE e da adaptação dos novos países-membros à PAC - explicações mais detalhadas sobre a modelagem se encontram em Oliveira (2005). As medidas modeladas foram:

a) A eliminação das tarifas de importação entre os novos países da UE e entre os mesmos e os antigos membros da União Européia;

b) A equalização de tarifas externas dos novos membros com a dos antigos membros;

c) Aspectos específicos relacionados à agricultura e à expansão:

c1) cota de produção de leite;

c2) subsídios à produção da pecuária e aos cultivos anuais;

c3) subsídio ao abate bovino.

d) Aspectos específicos da reforma da PAC:

d1) descasamento parcial dos pagamentos diretos;

d2) descasamento total.

\subsubsection{Eliminação e equalização de tarifas externas}

A remoção de tarifas de importação entre os novos membros e entre estes e os antigos membros foi implementada através de choque na variável que representa as alíquotas de importação setoriais nas regiões que compõem a UE.

A equalização de tarifas externas dos novos membros com a dos antigos membros seguiu a recomendação de Jensen e Frandsen (2003). Implementaram-se mudanças nas alíquotas de importação setoriais para transformá-las nas tarifas vigentes para cada setor nos antigos paísesmembros. O choque se deu na variável que representa a potência da alíquota de importação de todos os setores, das regiões que compreendem os novos membros, que importam das que não são membros da UE. 
2.3.2. Aspectos específicos relacionados à implantação da PAC nos novos membros

A integração de novos membros na UE e a extensão da PAC aos mesmos implicam na implantação de cotas de produção de leite nos países recém-admitidos no bloco europeu. A implementação de cotas para o leite no GTAP segue as recomendações feitas por Jensen, Frandsen e Bach (1998) e Conforti, Filippis e Salvatici (2002).

O estabelecimento das cotas se dá através da exogeneização da quantidade produzida e da introdução de choque para cada uma das regiões que compreendem os novos membros da UE. O valor do choque será o suficiente para levar a produção observada em 2001 aos níveis da cota estabelecida. A introdução da cota leva à criação da variável que expresse a potência da renda da cota que será endogeneizada no modelo.

Os subsídios à produção animal e vegetal nos novos países-membros consistem no pagamento de prêmio para o rebanho de corte (total do efetivo e vacas em amamentação), pagamentos adicionais à pecuária de corte e prêmios para cultivos anuais. O subsídio aos cultivos anuais é dado em função de área e rendimento físico de referência pré-determinados. Essa subvenção é distribuída entre os setores trigo, ocerea (outros cereais, inclusive o milho) e oleagi (oleaginosas). Como são referentes ao processo produtivo e não à comercialização do produto, esses subsídios à produção animal e vegetal foram modelados como subvenção ao fator de produção terra, seguindo a orientação de Jensen, Frandsen e Bach (1998). Operacionalmente, criou-se uma variável, que respondeu pela variação linear do subsídio recebido e recebeu o choque. Eis a sua definição:

$$
\begin{aligned}
& \text { (all,i,TERRA)(all,j,BOI) (all,r,NOVOSUE) } \\
& 100 * \text { del_LP(i,j,r) = VFM(i,j,r)*[qfe(i,j,r) }+ \text { pmes(i,j,r)]-VFA(i,j,r)* } \\
& \text { [qfe(i,j,r) + pfe(i,j,r)] }
\end{aligned}
$$

Em que:

i é o insumo utilizado, neste caso a terra;

j são os setores em questão, neste caso, BOI é o conjunto dos setores "bovovi”, “trigo”, “ocerea” e "oleagi”; 
r são as regiões que compõem o conjunto NOVOSUE, os novos membros, "Poloni" e "RUE10";

del_LP(i,j,r) é a variável criada no modelo para medir a variação do subsídio em nível (não em variação percentual) dado ao setor “j” da região "r" através da utilização do insumo proveniente do setor "i";

VFM(i,j,r) é o valor do insumo “i”, utilizado no setor ' $\mathrm{j}$ ” da região "r" a preços de mercado;

qfe(i,j,r) é a variação percentual da quantidade utilizada do insumo "i" no setor "j" da região "r";

pmes(i,j,r) é a variação percentual do preço do insumo "i" no setor “j” da região "r", a preços de mercado;

VFA(i,j,r) é o valor do insumo "i”, utilizado no setor “ $j$ ” da região " $r$ ” a preços pagos pelo setor “ $\mathrm{j}$ ”;

pfe(i,j,r) é a variação percentual do preço do insumo "i” no setor “j” da região "r”, a preços pagos pelo setor “j”.

O subsídio ao abate de animais nos novos membros da UE é calculado em função do tipo e número de cabeças abatidas. Essa transferência, por estar vinculada à venda do animal para abate, é modelada como subsídio direto à produção. O choque se dá na variável que representa a potência da alíquota do subsídio recebido pelo produtor.

\subsubsection{Aspectos específicos da reforma da PAC}

A medida mais importante referente à última rodada de modificação da PAC é o descasamento dos pagamentos diretos, modelado como subsídio ao insumo terra, conforme proposto por Conforti, Filippis e Salvatici (2002). Uma rotina de programação foi gerada para se estabelecer o valor do choque ao subsídio pago ao fator terra, por setor ${ }^{3}$, por região, com vista à sua implementação. Foi calculada a soma dos subsídios vigentes para as atividades agropecuárias e os mesmos foram

\footnotetext{
${ }^{3}$ Os setores considerados para o descasamento foram: trigo, ocerea (outros cereais, inclusive milho), fruveg (frutas e vegetais, inclusive laranja e sucos), oleagi (oleaginosas, inclusive soja, farelo e óleo), fibveg (fibras vegetais), ccdcul (café, cacau e demais cultivos), bovovi (bovinos, ovinos, caprinos, eqüinos e muares), frasui (frangos, suínos e demais animais), leite, arroz, acucar (cultivo de cana-de-açúcar e beterraba e produção industrial de açúcar).
} 
redistribuídos entre os setores, considerando o uso do fator terra como fator de ponderação. Foram considerados os subsídios nos setores agropecuários dados aos insumos intermediários (terra, trabalho e capital e produtos dos setores agropecuários utilizados como insumo) e ao produto comercializado. Considerou-se, ainda, o subsídio adicional vigente a partir da expansão de 2004 e da vigência da PAC nos novos países-membros, que é a soma dos subsídios contabilizados para pecuária de corte, cultivos anuais e abate de animais. O choque dado correspondeu à diferença entre o valor calculado do subsídio após sua redistribuição e o valor atual do mesmo, aplicado na variável "del_LP”, descrita na expressão (1).

Três cenários simplificados alternativos de descasamento foram adotados: o descasamento total, parcial e a ausência de descasamento. O descasamento total consistiu na total retirada dos subsídios acima mencionados e o descasamento parcial, na retirada e redistribuição de apenas metade dos subsídios. Para os três cenários, foram consideradas as medidas relacionadas à expansão da UE. O descasamento foi aplicado em todas as regiões que compreendem a atual UE: os antigos e os novos países-membros. As exceções ao descasamento não foram levadas em conta neste trabalho, pela necessidade de se simplificar e tornar operacionalizável a metodologia adotada. A implantação progressiva, em fases, prevista para a PAC nesses novos países não foi considerada. O estudo se refere ao impacto final da expansão e dos diferentes cenários de descasamento em comparação com a situação inicial, antes das medidas.

\subsubsection{Fechamento do modelo}

O fechamento padrão utilizado pelo GTAP e também adotado neste trabalho é de curto prazo. O estoque de capital é considerado fixo. O modelo gera variação de investimento nas diferentes regiões, mas essa informação só é um indicativo de possibilidade de investimentos futuros - o modelo, por ser estático, não é alimentado por essas informações. A influência do investimento no modelo se dá através da demanda de bens que se destinam ao mesmo.

O GTAP permite duas alternativas, escolhidas através de variável 
binária, para a alocação do investimento entre as regiões. A primeira abordagem distribui o investimento entre as regiões considerando a variação da taxa de retorno do capital constante entre todas as regiões. A segunda assume que a proporção do estoque de capital é fixa entre as regiões estudadas. Este estudo adota a primeira abordagem.

Preços e quantidades de commodities são considerados endógenos, como a renda nacional. Estoque de terra, trabalho e capital e as variáveis de mudança tecnológica são exógenos ao modelo. O capital e a mão-de-obra se movimentam livremente entre setores, mas não entre regiões. A terra se movimenta entre setores, mas de maneira limitada, em função da elasticidade de transformação (sluggish commodity). O ambiente considerado é de livre concorrência e sem economia de escala. Assume-se lucro zero para as atividades produtivas e pleno emprego. O fechamento é, assim, tipicamente neoclássico.

\section{Resultados e discussão}

O impacto da expansão da UE no valor do Produto Interno Bruto (PIB) das diferentes regiões estudadas é modesto. A redução desse efeito tem relação com o fechamento de curto prazo utilizado, que limita a amplitude das respostas obtidas. O PIB da Polônia decresce 0,3\% por conta da expansão, sob os três cenários de descasamento, mostrando que, de maneira agregada, este país tem redução da atividade econômica com a expansão da UE. O significativo decréscimo na produção de leite do país por conta do ajuste à cota imposta pela PAC é uma das explicações dessa diminuição. O efeito da expansão nos demais membros da UE é diminuto. O menor peso econômico dos novos países no conjunto da UE explica esse fato. O impacto agregado na economia brasileira é também reduzido, porém, crescente com o descasamento, indicando que o Brasil pode obter ganhos com a queda dos subsídios à produção agrícola no continente europeu (Tabela 3). 
Tabela 3. Efeitos da expansão da União Européia. Variação percentual real do produto, em valor, nas diferentes regiões estudadas sob cenários alternativos de descasamento dos pagamentos diretos

\begin{tabular}{lccc}
\hline & \multicolumn{3}{c}{ Cenários de descasamento } \\
\cline { 2 - 4 } & Zero & parcial & total \\
\hline Brasil & 0,0 & 0,1 & 0,2 \\
Poloni & $-0,3$ & $-0,3$ & $-0,3$ \\
RUE10 & 0,0 & 0,0 & 0,1 \\
Escand & $-0,1$ & $-0,1$ & $-0,1$ \\
Atlant & $-0,1$ & $-0,1$ & $-0,1$ \\
Aleaus & 0,0 & 0,0 & 0,0 \\
Franca & 0,0 & 0,0 & 0,0 \\
Medite & 0,0 & 0,0 & 0,0 \\
Nafta & 0,0 & 0,0 & 0,0 \\
Argent & $-0,1$ & 0,0 & 0,1 \\
China & 0,0 & 0,0 & 0,0 \\
RAsia & 0,0 & 0,0 & 0,0 \\
RAmeri & 0,0 & 0,0 & 0,0 \\
ROW & 0,1 & 0,1 & 0,1 \\
\hline
\end{tabular}

Fonte: Dados da pesquisa

Observa-se significativo aumento das exportações agregadas nos novos membros da UE. Elas crescem mais de $9 \%$ na Polônia e mais de $4 \%$ nos demais novos Estados-Membros, sob os três cenários de descasamento. O impacto nas demais regiões estudadas, inclusive no Brasil, não é significativo (Tabela 4). 
Tabela 4. Efeitos da expansão da União Européia. Variação percentual do valor real das exportações nas diferentes regiões estudadas sob cenários alternativos de descasamento dos pagamentos diretos

\begin{tabular}{l|c|c|c}
\hline \multirow{2}{*}{} & \multicolumn{3}{c}{ cenários de descasamento } \\
\cline { 2 - 4 } \multicolumn{1}{c}{ Zero } & parcial & total \\
\hline Brasil & 0,0 & $-0,1$ & $-0,1$ \\
Poloni & 9,2 & 9,1 & 9,6 \\
RUE10 & 4,5 & 4,4 & 4,6 \\
Escand & $-0,1$ & $-0,1$ & 0,0 \\
Atlant & $-0,1$ & 0,0 & 0,1 \\
Aleaus & 0,0 & 0,0 & 0,0 \\
Franca & 0,0 & 0,0 & 0,0 \\
Medite & 0,0 & 0,2 & 0,5 \\
Nafta & 0,0 & $-0,1$ & $-0,2$ \\
Argent & $-0,1$ & $-0,1$ & 0,0 \\
China & 0,0 & 0,0 & $-0,1$ \\
RAsia & 0,0 & $-0,1$ & $-0,2$ \\
RAmeri & 0,0 & $-0,1$ & $-0,1$ \\
ROW & 0,1 & 0,0 & 0,0 \\
\hline
\end{tabular}

Fonte: Dados da pesquisa.

O impacto nas importações totais das diferentes regiões estudadas é mais intenso nos novos países-membros. As importações aumentam cerca de $3 \%$ na Polônia e $5 \%$ nos demais novos membros, sob os três cenários. O fato de a expansão se dar nessas regiões explica a maior magnitude do impacto observada nas mesmas. O maior peso econômico dos antigos em comparação com os novos membros está de acordo com o menor impacto observados nesses primeiros países (Tabela 5). 
Tabela 5. Efeitos da expansão da União Européia. Variação percentual do valor real das importações nas diferentes regiões estudadas sob cenários alternativos de descasamento dos pagamentos diretos

\begin{tabular}{lrrr}
\hline & \multicolumn{3}{c}{ cenários de descasamento } \\
\cline { 2 - 4 } & zero & parcial & total \\
\hline Brasil & $-0,1$ & 0,1 & 0,3 \\
Poloni & 3,6 & 3,0 & 2,9 \\
RUE10 & 5,1 & 4,9 & 4,8 \\
Escand & $-0,1$ & $-0,1$ & $-0,1$ \\
Atlant & $-0,1$ & $-0,1$ & $-0,1$ \\
Aleaus & 0,1 & 0,1 & 0,0 \\
Franca & 0,0 & $-0,1$ & $-0,1$ \\
Medite & 0,1 & 0,1 & 0,2 \\
Nafta & 0,0 & 0,0 & 0,0 \\
Argent & $-0,1$ & 0,0 & 0,2 \\
China & 0,0 & 0,0 & 0,0 \\
RAsia & 0,0 & 0,0 & $-0,1$ \\
RAmeri & 0,0 & 0,0 & 0,0 \\
ROW & 0,1 & 0,1 & 0,1 \\
\hline
\end{tabular}

Fonte: Dados da pesquisa

A expansão da União Européia tem efeito na produção agregada mundial dos diversos setores estudados. O mais significativo é a queda na produção de leite em $0,4 \%$, devido à imposição de cotas nos novos membros, mesmo sem descasamento. A expansão sob descasamento diminui subsídios e aprofunda a diminuição da produção em setores muito protegidos na EU, como de laticínios e de carne bovina. A produção mundial de leite cai $0,6 \%$ e a de bovinos, ovinos e de outros animais (bovovi), 0,8\% sob descasamento total. Isso mostra o impacto global de políticas agrícolas da UE, pelo expressivo volume de produção agrícola observado no continente europeu (Tabela 6). 
Tabela 6. Efeitos da expansão da União Européia. Variação percentual da quantidade produzida em diferentes setores, totais mundiais, sob cenários alternativos de descasamento dos pagamentos diretos

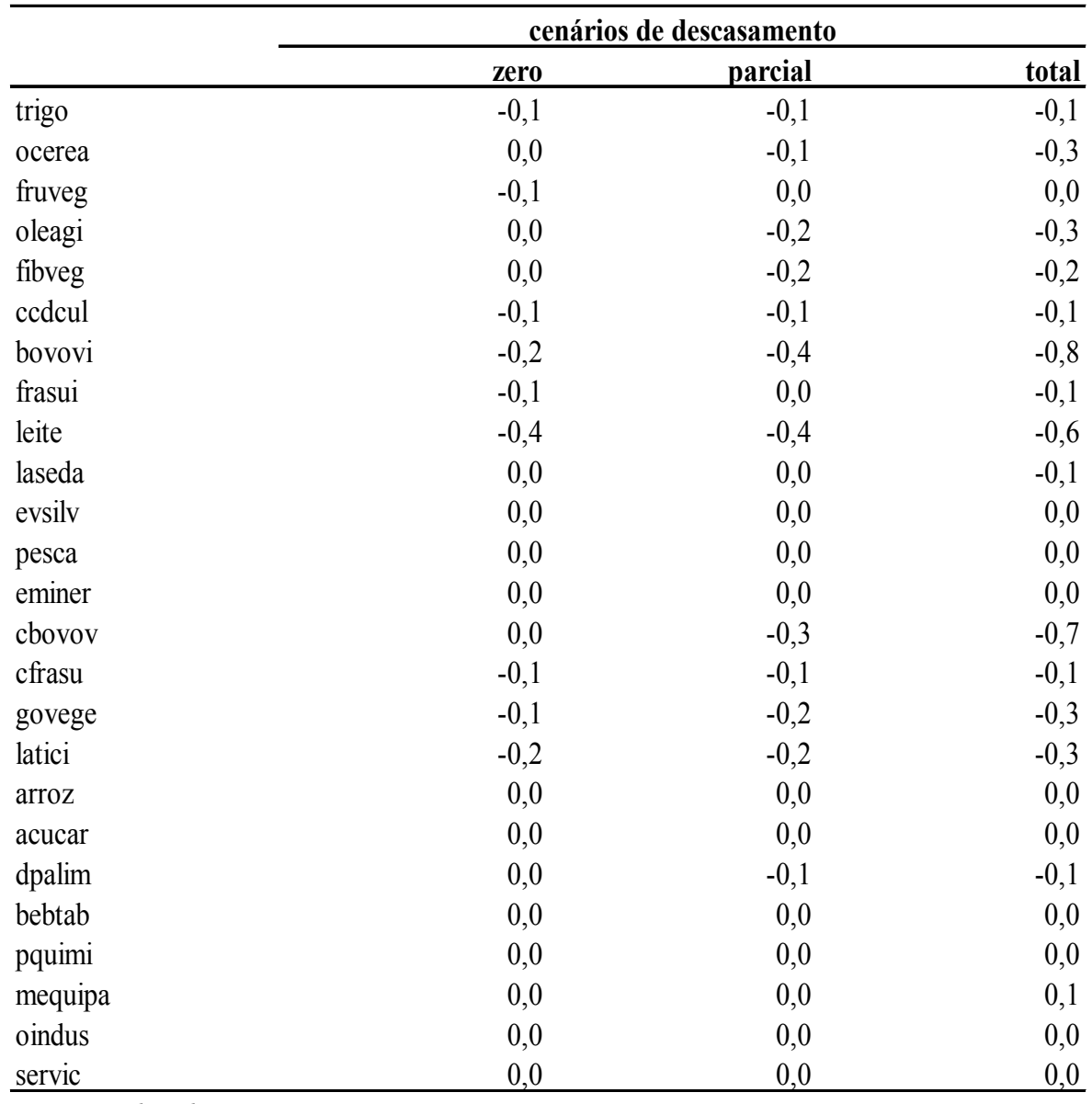

Fonte: Dados da pesquisa

A expansão da UE tem impacto nos preços mundiais dos diversos setores estudados. Alguns apresentam queda na produção e, como conseqüência, aumento nos preços. As cotações mundiais de leite aumentam entre 2,1\% e 3,4 \% nos diferentes cenários. Os preços de bovinos, ovinos e outros animais (bovovi) sobem até $4,1 \%$ sob descasamento total dos pagamentos diretos. As cotações de laticínios (latici), carne bovina, ovina e de outros animais (cbovov) também se elevam sob este mesmo cenário (Tabela 7). 
Tabela 7. Efeitos da expansão da União Européia. Variação percentual dos preços médios mundiais de produtos dos diferentes setores sob cenários alternativos de descasamento dos pagamentos diretos

\begin{tabular}{lrrr}
\hline & \multicolumn{3}{c}{ cenários de descasamento } \\
\cline { 2 - 4 } & zero & parcial & total \\
\hline trigo & $-0,6$ & 0,3 & 0,6 \\
ocerea & $-0,6$ & 0,3 & 0,6 \\
fruveg & 0,2 & $-0,2$ & $-0,2$ \\
oleagi & $-0,2$ & 1,0 & 2,1 \\
fibveg & 0,0 & 0,3 & 0,5 \\
ccdcul & 0,2 & 0,0 & 0,2 \\
bovovi & $-0,4$ & 1,8 & 4,1 \\
frasui & 0,2 & 0,1 & 0,1 \\
leite & 2,1 & 2,6 & 3,4 \\
laseda & 0,0 & 0,1 & 0,2 \\
evsilv & 0,0 & 0,0 & 0,0 \\
pesca & 0,0 & $-0,1$ & $-0,1$ \\
eminer & 0,0 & 0,0 & $-0,1$ \\
cbovov & 0,0 & 0,7 & 1,7 \\
cfrasu & $-0,2$ & 0,0 & 0,1 \\
govege & 0,1 & 0,3 & 0,8 \\
latici & $-0,1$ & 0,8 \\
arroz & 0,4 & 0,5 & 0,0 \\
acucar & 0,0 & 0,0 & 0,0 \\
dpalim & 0,1 & 0,0 & 0,0 \\
bebtab & $-0,1$ & $-0,1$ \\
pquimi & $-0,1$ & $-0,0$ & $-0,1$ \\
mequipa & 0,0 & $-0,1$ & $-0,1$ \\
oindus & 0,0 & $-0,1$ \\
servic & 0,0 & $-0,1$ \\
\hline Font: Da, & & $-0,1$ \\
\hline
\end{tabular}

Fonte: Dados da pesquisa

A expansão da UE sem descasamento proporciona impactos setoriais diferenciados no Brasil. A produção de oleaginosas (oleagi) e outros cereais, inclusive milho (ocerea), apresenta diminuição de $0,8 \%$, resultado da perda de mercado externo por conta do desvio de comércio decorrente da expansão. Por outro lado, a produção de café, cacau e outros cultivos (ccdcul) cresce $0,8 \%$, devido à abertura de mercado 
para o produto brasileiro. Essa abertura, por sua vez, ocorre nos novos países pela necessidade de se adequar à tarifa externa comum comunitária, menor que a vigente nos mesmos. O descasamento desprotege alguns setores da EU, como de carnes e oleaginosas, favorecendo a posição brasileira no mercado mundial. A produção brasileira de oleaginosas (oleagi) aumenta $5,4 \%$ e a de carne bovina, ovina e de outros animais (cbovov), 2,2\%, com a expansão sob descasamento total dos pagamentos diretos (Tabela 8).

Tabela 8. Efeitos da expansão da União Européia. Variação percentual da produção setorial sob diferentes cenários de descasamento, Brasil, setores selecionados

\begin{tabular}{|c|c|c|c|}
\hline & \multicolumn{2}{|c|}{ cenários de descasamento } & \multirow[b]{2}{*}{ total } \\
\hline & zero & parcial & \\
\hline trigo & $-0,2$ & $-0,1$ & $-0,1$ \\
\hline ocerea & $-0,8$ & $-0,4$ & $-0,3$ \\
\hline fruveg & 0,1 & $-0,6$ & $-1,0$ \\
\hline oleagi & $-0,8$ & 2,5 & 5,4 \\
\hline fibveg & 0,0 & 0,5 & 0,5 \\
\hline ccdcul & 0,8 & $-0,1$ & $-0,5$ \\
\hline bovovi & $-0,2$ & 0,6 & 1,5 \\
\hline frasui & 0,0 & $-0,1$ & 0,0 \\
\hline leite & 0,0 & 0,0 & $-0,1$ \\
\hline laseda & 0,3 & $-0,9$ & $-2,3$ \\
\hline evsilv & 0,0 & 0,0 & 0,0 \\
\hline pesca & 0,0 & 0,0 & $-0,1$ \\
\hline eminer & 0,0 & $-0,1$ & $-0,2$ \\
\hline cbovov & $-0,2$ & 0,8 & 2,2 \\
\hline cfrasu & 0,0 & $-0,6$ & $-1,0$ \\
\hline govege & 0,0 & 0,1 & 0,1 \\
\hline latici & 0,0 & 0,0 & 0,0 \\
\hline arroz & 0,0 & $-0,1$ & $-0,1$ \\
\hline acucar & 0,0 & $-0,1$ & $-0,3$ \\
\hline dpalim & $-0,1$ & $-0,1$ & $-0,1$ \\
\hline bebtab & 0,0 & 0,0 & 0,0 \\
\hline pquimi & 0,0 & $-0,1$ & $-0,2$ \\
\hline mequipa & 0,0 & $-0,2$ & $-0,5$ \\
\hline oindus & 0,0 & $-0,2$ & $-0,4$ \\
\hline servic & 0,0 & 0,0 & 0,0 \\
\hline
\end{tabular}

Fonte: Dados da pesquisa 
A expansão da UE sem descasamento proporciona redução das exportações em alguns setores brasileiros. É o desvio de comércio causado pela remoção de barreiras alfandegárias entre os novos e os antigos membros da União Européia. As exportações de milho e outros cereais (ocerea) decrescem 2,7\% e as de carne bovina, ovina e de outros animais (cbovov), 1,8\%. Os embarques de café, cacau e outros cultivos (ccdcul) são motivados pelo estabelecimento de uma tarifa externa comum, que favorece a entrada do produto brasileiro nos novos membros, e crescem 2,3\%. A exportação de lácteos (latici), embora incipiente, aumenta 1,5\%, como esperado, já que a expansão é acompanhada de restrição à produção leiteira nos novos membros.

A expansão com descasamento total beneficia, no Brasil, setores muito protegidos na EU, como de oleginosas (oleagi) e carne de bovinos, ovinos e outros animais (cbovov), cujas exportações aumentam mais de $10 \%$. Os impactos relativos negativos mais intensos são sentidos em frutas e vegetais (fruveg), com decréscimo de $3 \%$, e no valor das exportações de carne de frango e suínos (cfrasu), com queda de 2,1\% (Tabela 9). 
Tabela 9. Efeitos da expansão da União Européia. Variação percentual do valor real FOB das exportações brasileiras nos diferentes setores estudados sob cenários alternativos de descasamento dos pagamentos diretos

\begin{tabular}{lrrr}
\hline & \multicolumn{3}{c}{ cenários de descasamento } \\
\cline { 2 - 4 } & zero & parcial & total \\
\hline ocerea & $-2,7$ & $-1,3$ & $-1,0$ \\
fruveg & 0,3 & $-1,8$ & $-3,0$ \\
oleagi & $-1,8$ & 5,6 & 12,1 \\
fibveg & 0,1 & 2,5 & 3,5 \\
ccdcul & 2,3 & 0,1 & $-0,6$ \\
frasui & 0,4 & $-0,2$ & $-0,5$ \\
laseda & 0,3 & $-0,8$ & $-2,1$ \\
evsilv & 0,3 & $-0,2$ & $-0,7$ \\
pesca & 0,0 & $-0,1$ & $-0,2$ \\
eminer & 0,0 & 0,0 & 0,0 \\
cbovov & $-1,8$ & 6,6 & 16,8 \\
cfrasu & $-0,1$ & $-1,3$ & $-2,1$ \\
govege & 0,1 & 0,1 & 0,0 \\
latici & 1,5 & 1,6 & 2,1 \\
arroz & $-0,4$ & $-1,0$ & $-1,7$ \\
acucar & 0,1 & $-0,3$ & $-0,7$ \\
dpalim & $-0,6$ & $-0,8$ & $-0,9$ \\
bebtab & 0,4 & 0,2 & 0,1 \\
pquimi & 0,2 & $-0,3$ & $-0,8$ \\
mequipa & 0,2 & $-0,5$ & $-1,2$ \\
oindus & 0,0 & $-0,5$ & $-0,6$ \\
servic & 0,1 & $-0,3$ &
\end{tabular}

Fonte: Dados da pesquisa

Nota: Foram incluídos apenas setores com valor de exportação acima de US\$ 10 milhões em 2001.

Os maiores impactos absolutos da expansão sem descasamento nas exportações brasileiras ocorrem no setor de café, cacau e outros cultivos (ccdcul), com aumento de US\$ 61 milhões no valor exportado. Já os embarques de oleaginosas (oleagi) decrescem US\$ 52 milhões, recuando de US\$ 2.856 milhões para US $\$ 2.804$ milhões. A expansão com descasamento total gera maiores impactos absolutos nas exportações setoriais brasileiras. Os embarques de oleaginosas saltam de US\$2.856 milhões para US\$ 3.201 milhões, um incremento de US\$ 345 milhões. Outro setor que acelera suas vendas externas é o de carne bovina, ovina 
e de outros animais (cbovov), que tem aumento de US\$ 198 milhões. As exportações de vestuário, têxteis, automóveis, eletrônicos e outras indústrias (oindus) apresentam decréscimo de US\$ 296 milhões. Este elevado valor se explica pelo total exportado pelo setor (quase US\$ 29 bilhões em 2001) e pelo fechamento utilizado no modelo, que mantém fixos estoques de capital, terra e trabalho em cada região, induzindo o aumento observado em um dado setor a ser compensado pela diminuição em outro (Tabela 10).

Tabela 10. Efeitos da expansão da União Européia. Valor inicial, variação percentual e absoluta do valor real das exportações brasileiras nos diferentes setores estudados sob cenários alternativos de descasamento dos pagamentos diretos

\begin{tabular}{|c|c|c|c|c|c|c|c|}
\hline \multirow[t]{3}{*}{ setor } & \multicolumn{4}{|c|}{ valor expansão sem descasamento } & \multicolumn{3}{|c|}{ expansão com desc. total } \\
\hline & \multirow{2}{*}{$\begin{array}{r}\text { inicial } \\
\text { (USS } \\
\text { milhões) }\end{array}$} & \multicolumn{2}{|c|}{$\begin{array}{c}\text { variação } \\
\text { percentual absoluta }\end{array}$} & \multirow{2}{*}{$\begin{array}{c}\begin{array}{c}\text { valor } \\
\text { final }\end{array} \\
\text { hões) }\end{array}$} & \multicolumn{2}{|c|}{$\begin{array}{c}\text { variacão } \\
\text { percentual absoluta }\end{array}$} & $\begin{array}{r}\text { valor } \\
\text { final }\end{array}$ \\
\hline & & $(\%)$ & (US\$ m & & $(\%)$ & (US\$ n & hões) \\
\hline 1 trigo & 1 & $-2,3$ & 0 & 1 & 2,1 & 0 & 1 \\
\hline 2 ocerea & 728 & $-2,7$ & -19 & 708 & $-1,0$ & -8 & 720 \\
\hline 3 fruveg & 449 & 0,3 & 1 & 450 & $-3,0$ & -14 & 435 \\
\hline 4 oleagi & 2.856 & $-1,8$ & -52 & 2.804 & 12,1 & 345 & 3.201 \\
\hline 5 fibveg & 180 & 0,1 & 0 & 180 & 3,5 & 6 & 186 \\
\hline 6 ccdcul & 2.613 & 2,3 & 61 & 2.674 & $-0,6$ & -17 & 2.597 \\
\hline 7 bovovi & 6 & $-1,2$ & 0 & 5 & 10,0 & 1 & 6 \\
\hline 8 frasui & 173 & 0,4 & 1 & 173 & $-0,5$ & -1 & 172 \\
\hline 9 leite & 1 & 1,0 & 0 & 1 & $-100,0$ & -1 & 0 \\
\hline 10 laseda & 35 & 0,3 & 0 & 35 & $-2,1$ & -1 & 34 \\
\hline 11 evsilv & 41 & 0,3 & 0 & 41 & $-0,7$ & 0 & 41 \\
\hline 12 pesca & 44 & 0,0 & 0 & 44 & $-0,2$ & 0 & 44 \\
\hline 13 eminer & 3.860 & 0,0 & 0 & 3.860 & 0,1 & 2 & 3.862 \\
\hline 14 cbovov & 1.178 & $-1,8$ & -21 & 1.157 & 16,8 & 198 & 1.376 \\
\hline $15 \mathrm{cfrasu}$ & 1.769 & $-0,1$ & -1 & 1.768 & $-2,2$ & -38 & 1.731 \\
\hline 16 govege & 608 & 0,1 & 1 & 608 & 0,0 & 0 & 608 \\
\hline 17 latici & 38 & 1,5 & 1 & 39 & 2,1 & 1 & 39 \\
\hline 18 arroz & 11 & $-0,4$ & 0 & 10 & $-1,7$ & 0 & 10 \\
\hline 19 acucar & 1.484 & 0,2 & 2 & 1.486 & $-0,7$ & -10 & 1.474 \\
\hline 20 dpalim & 4.018 & $-0,6$ & -23 & 3.995 & $-1,0$ & -38 & 3.980 \\
\hline 21 bebtab & 78 & 0,4 & 0 & 78 & 0,1 & 0 & 78 \\
\hline 22 pquimi & 4.318 & 0,2 & 8 & 4.325 & $-0,8$ & -35 & 4.282 \\
\hline 23 mequipa & 5.282 & 0,2 & 9 & 5.291 & $-1,2$ & -62 & 5.220 \\
\hline 24 oindus & 28.758 & 0,0 & -3 & 28.755 & $-1,0$ & -296 & 28.462 \\
\hline 25 servic & 8.671 & 0,1 & 7 & 8.678 & $-0,6$ & -55 & 8.617 \\
\hline Total & 67.195 & 0,0 & -29 & 67.166 & 0,0 & -23 & 67.173 \\
\hline
\end{tabular}

Fonte: Dados da pesquisa 
As importações brasileiras, por setor estudado, apresentam pouca influência pela expansão da UE. As variações são ligeiramente mais expressivas para setores do agronegócio. Esses setores, porém, não são mais importantes na pauta de importações brasileiras. O descasamento total aumenta a dispersão dos resultados observados. Isso condiz com um ambiente de maior mudança institucional, retratado por este cenário. As importações de gorduras e óleos vegetais (govege) diminuem $3,4 \%$ sob este último cenário, enquanto as compras de carne de frango, suínos e outros animais (cfrasu) aumentam 1,3\% (Tabela 11).

Tabela 11. Efeitos da expansão da União Européia. Variação percentual do valor real das importações brasileiras nos diferentes setores estudados sob cenários alternativos de descasamento dos pagamentos diretos

\begin{tabular}{lrrr}
\hline & \multicolumn{2}{c}{ cenários de descasamento } & total \\
\cline { 2 - 4 } & zero & parcial & 0,4 \\
\hline trigo & $-0,1$ & 0,1 & 0,4 \\
ocerea & $-0,4$ & 0,1 & 0,5 \\
fruveg & $-0,1$ & 0,2 & 1,6 \\
oleagi & $-0,1$ & 0,7 & 0,5 \\
fibveg & $-0,1$ & 0,2 & 1,0 \\
ccdcul & 0,1 & 0,5 & 1,5 \\
frasui & $-0,2$ & 0,6 & 0,4 \\
evsilv & $-0,1$ & 0,1 & 0,0 \\
pesca & $-0,1$ & $-0,1$ & $-0,4$ \\
eminer & 0,0 & $-0,2$ & 0,6 \\
cbovov & 0,0 & 0,3 & 1,3 \\
cfrasu & $-0,2$ & 0,5 & $-3,4$ \\
govege & $-0,1$ & $-1,7$ & 0,2 \\
latici & $-0,2$ & 0,0 & 0,9 \\
arroz & 0,0 & 0,4 & 0,6 \\
acucar & $-0,1$ & 0,2 & 0,4 \\
dpalim & $-0,1$ & 0,1 & 0,1 \\
bebtab & $-0,1$ & 0,0 & 0,2 \\
pquimi & 0,0 & 0,1 & 0,4 \\
mequipa & 0,0 & 0,2 & 0,3 \\
oindus & 0,0 & 0,1 & 0,3 \\
servic & $-0,1$ & 0,1 &
\end{tabular}

Fonte: Dados da Pesquisa

Nota: Foram incluídos apenas setores com valor de importação acima de US\$ 10 milhões em 2001 
Os maiores impactos das medidas estudadas no bem-estar são observados, como esperado, nos países-membros da UE. O decréscimo na Polônia é expressivo, sempre acima de US $\$ 2,2$ bilhões, com ou sem descasamento, sendo consoante com o recuo no produto esperado para o país. O acréscimo de bem-estar observado em algumas regiões que compreendem os antigos membros aumenta com a progressão do descasamento, atingindo mais de US $\$ 1,3$ bilhão sob descasamento total em quatro destas regiões. Esse é um indicador importante, que mostra que o descasamento, ainda que tenha impacto negativo na produção agropecuária européia, proporciona aumento de bem-estar gerado pela realocação dos recursos produtivos. Os impactos no Brasil são pequenos, quase nulos, sem o descasamento. A expansão sob descasamento total proporciona impacto mais significativo, de US\$ 195,8 milhões (Tabela 12).

Tabela 12. Efeitos da expansão da União Européia. Variação absoluta do bemestar nas diferentes regiões estudadas sob diferentes cenários de descasamento, em milhões de dólares, em 2001

\begin{tabular}{lrrr}
\hline & \multicolumn{3}{c}{ cenários de descasamento } \\
\cline { 2 - 4 } & zero & parcial & total \\
\hline Brasil & $-6,7$ & 87,5 & 195,8 \\
Poloni & $-2.396,6$ & $-2.252,7$ & $-2.435,2$ \\
RUE10 & $-701,1$ & $-636,2$ & $-758,9$ \\
Escand & 66,0 & 215,9 & 392,1 \\
Atlant & $-74,0$ & 900,6 & $1.658,7$ \\
Aleaus & 447,4 & $1.163,9$ & $1.783,4$ \\
Franca & 79,1 & 753,7 & $1.315,1$ \\
Medite & 513,3 & $1.188,7$ & $1.946,9$ \\
Nafta & $-28,8$ & 143,3 & 314,8 \\
Argent & $-10,9$ & 35,3 & 82,4 \\
China & 53,5 & 25,7 & $-4,1$ \\
RAsia & $-7,4$ & $-7,8$ & 7,5 \\
RAmeri & 8,4 & 5,0 & 18,4 \\
ROW & 532,7 & 546,5 & 606,5 \\
\hline
\end{tabular}

Fonte: Dados da pesquisa 


\section{Conclusões}

O presente trabalho analisou os impactos da expansão da União Européia em 2004 no agronegócio brasileiro. Numa primeira etapa, analisou-se o processo integração européia com a eliminação de barreiras tarifárias, harmonização de tarifa externa comum e implementação da PAC nos novos países-membros. A segunda etapa consistiu na reforma da PAC, que ocorre paralelamente ao processo de expansão e tem como principal medida o descasamento dos pagamentos diretos recebidos pelos produtores rurais. Como tais medidas redundam em choque exógeno à economia brasileira, os impactos no comércio exterior são maiores que os observados na produção nacional tanto em nível agregado como setorial.

Os maiores impactos observados, como era de se esperar, se dão no âmbito da própria UE, com ênfase nos novos países-membros, que são os que mais sofrem as mudanças da expansão de 2004. Alguns resultados agregados mundiais são expressivos, mas, muitas vezes, se concentram na própria União Européia. O impacto agregado na economia brasileira também é reduzido, porém, crescente com o descasamento, indicando que o País pode obter ganhos com a redução dos subsídios à produção no continente europeu.

A produção mundial de alguns setores, como de leite, carne bovina, ovina e de outros animais (cbovov), cai sob descasamento total. Isso confirma o impacto global de políticas agrícolas da UE, pelo expressivo volume de produção no continente europeu. A política da UE interessa, então, ao mundo todo, pois seus efeitos são sentidos globalmente. Esse interesse se reveste de maior importância no Brasil, que tem conquistado importante posição no comércio internacional de produtos do agronegócio. É de primordial importância estudos dessa natureza que visam acompanhar a evolução da PAC de outras medidas que possam afetar a produção e as exportações de produtos agropecuários brasileiros.

O processo de expansão européia em 2004 traz potenciais impactos na economia brasileira que valem a pena serem considerados ao se planejar políticas públicas de fomento setorial, comércio exterior e pesquisa. Considerar esses impactos é também importante para os agentes privados, como subsídio à tomada de decisão no agronegócio. 
Os resultados do trabalho identificam oportunidades que podem ser de grande valia para o agronegócio brasileiro. O setor de laticínios, por exemplo, tem um potencial de expansão de exportações, sob ausência ou presença de descasamento. Embora tenha pouca participação na pauta de exportações brasileiras, este setor tem elevado potencial de gerar renda e emprego, por ser intensivo na utilização de mão-de-obra (Oliveira e Miranda, 2004). Não seria, então, este mais um motivo para se pensar em política setorial de estímulo às exportações brasileiras de laticínios?

A expansão com descasamento total dos pagamentos diretos beneficia alguns setores estratégicos para as exportações brasileiras, como de carne de bovinos, ovinos e outros animais (cbovov) e oleaginosas (oleagi). No entanto, essa política européia prevê o descasamento em fases e com exceções, muitas delas, dependendo da escolha de cada país, exceções são possíveis. Não se pode garantir o alcance do descasamento e, portanto, a extensão de seus potenciais benefícios ao agronegócio brasileiro.

Uma grande lição do exercício do descasamento é que deixar de subsidiar a produção e continuar subsidiando o produtor pode ser uma medida inócua para reduzir as distorções introduzidas pela PAC no comércio internacional. A produção migra de um para outro setor, mas continua incompatível com a realidade de livre concorrência e formas leais de comércio internacional de ampla aceitação pela maioria das nações.

Mesmo de grande valor, os resultados devem ser interpretados com cautela. Referem-se a um resultado de um modelo teórico que, em suas suposições, reproduzem de maneira limitada o comportamento do mundo real. Alguns elementos institucionais que não são modelados podem interferir nos resultados das mudanças ocasionadas pela expansão de 2004. Entre eles, ressalta-se uma série de acordos bilaterais que a União Européia firma entre diferentes regiões do mundo, como o acordo com as ex-colônias do Caribe, África e do Pacífico. Exemplificando, o aumento de demanda por produtos do setor café, cacau e outros cultivos (ccdcul), na ausência de descasamento, não poderia ser suprido no âmbito destas preferências a ex-colônias européias ao invés de outras regiões, como o Brasil? 
A base de dados utilizada retrata a estrutura das economias regionais e as relações intersetoriais vigentes na época da elaboração da matriz de insumo-produto utilizada na mesma base - para o Brasil, de 1996. Ainda que os preços estejam atualizados para 2001, é esta estrutura da economia que responde aos choques propostos no trabalho. É notório o aumento da participação das exportações na composição da demanda de diversos setores do agronegócio brasileiro nos últimos anos. Oleaginosas, carne bovina e de frango são apenas exemplos. É de se esperar que os impactos aqui encontrados possam ter magnitude amplificada se confrontados com essa nova realidade do setor rural do Brasil.

A qualidade dos resultados depende da qualidade dos dados e equações utilizados. Estudos econométricos adicionais para determinar parâmetros utilizados na modelagem são importantes. O nível de agregação atualmente disponível no GTAP pode limitar a interpretação de resultados. Setores importantes para o agronegócio brasileiro, como de café, cacau e laranja, não se encontram isolados na base de dados. Esforços futuros de desagregação setorial da base de dados são recomendáveis.

\section{Referências bibliográficas}

ANTIMIANI, A.; SANTUCCIO, F. Mid-Term Review, enlargement, and effective market access in the EU: an evaluation in a CGE context. West Lafayette: GTAP, 2004. 25 p. (GTAP Resource, 1640).

BCHIR, H.; FONTAGNÉ, L.; ZANGHIERI, P. The impact of EU enlargement on member states: a CGE approach. Paris: Centre d'Etudes Prospectives et d'Informations Internationales, 2003. 54 p. (CEPII. Working Paper, 2003-10).

BINFIELD, J. et al. The Luxemburg CAP Reform Agreement: implications for UE and Irish agriculture. Disponível em: < http://tnet.teagasc. ie/fapri/downloads/pubs2003/luxag/paper1141003a.pdf > . Acesso em: 1 set. 2005.

BINFIELD, J.; WESTHOFF, P.; YOUNG II, R. Reforming the CAP: a partial equilibrium analysis of the MTR proposals. Durban, 2003. Disponív- 
el em: < http://www.fapri.missouri.edu/outreach/publications/2003/ FAPRI_UMC_Report_08_03.pdf > . Acesso em: 5 set. 2005.

BLANTON, T. FOIA law disclose british farm subsidies, now posted on web. Disponível em: < http://www.freedominfo.org/case/cap/ > . Acesso em 25 ago. 2005.

COCHRANE, N.; SEELEY, R. EU enlargement: implications for the new member countries, the United States, and world trade. Washington: United States Department of Agriculture, Economic Research Service, 2004. 20 p. (ERS. Outlook report, WRS040501).

CONFORTI, P.; FILIPPIS, F.; SALVATICI, L. The Mid-Term Review of the CAP: assessing the effects of the Commision proposals. Roma: Instituto Nazionale di Economia Agraria, 2002. 31 p. (INEA. Working Paper, 18).

CRONOLOGY: the history of the European Union: European citizenship. Disponível em: < http:/www.historiasiglo20.org/europe/cronologia. htm $>$ Consultado em 5 set. 2005.

DYKER, D.A. The dynamic impacts on the Central-Eastern European Economies of Accession to the European Union: social capability and technology absorption. Europe-Asie Studies, London, v. 53, n. 7, p. 1001-1021, 2001.

EUROPEAN UNION. Council Regulation (EC) 1782/ 2003 of 29 September 2003. Official Journal of the European Union, 21 Oct. 2003. p.L 270/1-L 270/69. Establishing common rules for direct support schemes under the common agricultural policy and establishing certain support schemes for farmers and amending Regulations.

FOOD AND AGRICULTURAL POLICY RESEARCH CENTER - FAPRI. Analysis of 2003 CAP reform agreement. Columbia, 2003. 16 p. (FAPRI Staff Report, 2-03).

GABRISH, H. Eastern enlargement of the European Union: macroeconomic effects in new Members States. Europe-Asia Studies, London, v. 49, n. 4, p. 567-590, Jun. 1997 
GLOBAL TRADE ANALYSIS PROJECT (GTAP). GTAP Disponível em $<$ https://www.gtap.agecon.purdue.edu/default.asp > Acesso em 1 dez. 2006.

HEROK, C.A.; LOTZE, H. Implications of an EU Eastern Enlargement under a new Common Agricultural Policy. Journal of Policy Modeling, v.22, n.6, p.661-690, 2000.

HERTEL, T.W. (Ed.). Global trade analysis: modeling and applications. Cambridge: University Press, 1997. 403 p.

HISTORY OF THE EUROPEAN UNION: Wikipedia, the free encyclopedia. Disponível em: < http:// www. en.wikipedia.org/wiki/History_ of_the_European_Union > Consultado em 5 set. 2005.

JENSEN, H. G.; FRANDSEN, S. O.; BACH, C. F. Agricultural and economy-wide effects of European enlargement: modelling the Common Agricultural Policy. Frederiksberg: Fodevareokonomist Institut, 1998. 40p. (SJFI. Working Paper, 11/1998).

JENSEN, H.G.; FRANDSEN, S.O. Implications of EU Accession of ten new members: the Copenhagen Agreement. Frederiksberg: Fodevareokonomist Institut, 2003. 52 p. (SJFI. Working Paper, 01/2003).

JENSEN, H.G.; FRANDSEN, S.O. Implications of Eastern European Accession and the 2003-reform of the CAP: consequences for individual member states. Disponível em: <www.gtap.agecon.purdue.edu/ resources/download/2689.pdf > . Acesso em: 9 set. 2004.

KEUSCHNIGG, C.; KEUSCHNIGG, M.; KOHLER, W. The German perspective on the eastern EU enlargement. World Economy, Amsterdam, v. 8, n. 6, p. 1013-1031, Apr. 2001.

KOHLER, W. Eastern enlargement of the EU: a comprehensive welfare assessment. Journal of Policy Modeling, Amsterdam, v. 26, n. 7, p. 865-888, Oct. 2004.

OLIVEIRA, S. J. M. A expansão da União Européia em 2004 e seus impactos sobre o agronegócio brasileiro. 2005. 170 p. Tese (Douto- 
rado em Economia Aplicada) - Escola Superior de Agricultura "Luiz de Queiroz”, Universidade de São Paulo, Piracicaba, 2005.

OLIVEIRA, S. J. M.; MIRANDA, S.H.G. Leite: oportunidades no mercado externo. Agroanalysis, Rio de Janeiro, v. 24, n. 7, p. 15-17, jul. 2004.

OXFAM Stop the dumping! How EU agricultural subsidies are damaging livelihoods in the developing world. Washington, 2002. 11p. (OXFAM. Briefing Paper, 31).

ORGANISATION FOR ECONOMIC CO-OPERATION AND DEVELOPMENT (OECD). Analysis of the 2003 CAP Reform. Paris, 2004. Disponível em: < http://www.oecd.org/dataoecd/62/42/32039793. pdf. > . Acesso em 22 jun. 2004.

PAAS, T.; TAFENAU, E. Regional trade clusters in promoting eastward enlargement of the European Union. Transition studies review, Milano, v. 12, n. 1, p. 77-90, 2005.

RAO, R. Blenheim and Bangalore: a tale of subsidies in two communities. Disponível em: < http://www.globalpolicy.com/ opinion/2005/0705bleinheim.htm > . Acesso em 23 ago. 2005.

THE CHURCHILL SOCIETY, LONDON. History of the EEC. Disponível em: < http://www.churchill-society-london.org.uk/eec.htm > Consultado em 5 set. 2005 . 